\title{
The molecular genetics of haemochromatosis
}

\author{
Gérald Le Gac ${ }^{1,2}$ and Claude Férec ${ }^{\star 1,2,3}$
}

\author{
${ }^{1}$ INSERM U613, Brest, France; ${ }^{2}$ Laboratoire National en Virologie et Biologie Moléculaire de l'Etablissement Français \\ du Sang, Brest, France; and ${ }^{3}$ Université de Bretagne Occidentale, Brest, France
}

The molecular basis of haemochromatosis has proved more complex than expected. After the 1996 identification of the main causative gene HFE and confirmation that most patients were homozygous for the founder $\mathrm{C} 282 \mathrm{Y}$ mutation, it became clear that some families were linked to rarer conditions, first named 'non-HFE haemochromatosis'. The genetics of these less common forms was intensively studied between 2000 and 2004, leading to the recognition of haemojuvelin (HJV), hepcidin (HAMP), transferrin receptor 2 (TFR2) and ferroportin-related haemochromatosis, and opening the way for novel hypotheses such as those related to digenic modes of inheritance or the involvement of modifier genes. Molecular studies of rare haemochromatosis disorders have contributed to our understanding of iron homeostasis. In turn, recent findings from studies of knockout mice and functional studies have confirmed that HAMP plays a central role in mobilization of iron, shown that HFE, TFR2 and HJV modulate HAMP production according to the body's iron status, and demonstrated that HAMP negatively regulates cellular iron efflux by affecting the ferroportin cell surface availability. These data shed new light on the pathophysiology of all types of haemochromatosis, and offer novel opportunities to comment on phenotypic differences and distinguish mutations.

European Journal of Human Genetics (2005) 13, 1172-1185. doi:10.1038/sj.ejhg.5201490;

published online 31 August 2005

Keywords: haemochromatosis; genetic heterogeneity; phenotypic heterogeneity; onset; iron homeostasis

Introduction - historical brief

The term haemochromatosis was coined by Von Recklinghausen $^{1}$ in 1889 to describe the association of an abnormal iron deposition in tissues with the clinical syndrome of cirrhosis, diabetes mellitus and bronze skin pigmentation reported by Trousseau 24 years earlier. ${ }^{2}$ A familial origin of haemochromatosis was first posited by Sheldon $^{3}$ in 1935 who, after conducting a comprehensive literature review, classed the disease as an inborn error of metabolism. After this elementary step, and despite the fact that the idiopathic (not acquired) origin of the disease remained a matter of debate for 40 more years, ${ }^{4}$ haemo-

*Correspondence: Professor C Férec, Laboratoire de Génétique Moléculaire, INSERM U613-EFS, Bretagne, Site de Brest, BP 454, 46, rue Félix Le Dantec, 29200 Brest, France.

Tel: + 332984450 64; Fax: + 332984305 55;

E-mail: Claude.Ferec@univ-brest.fr

Received 20 May 2005; revised 7 July 2005; accepted 12 July 2005; published online 31 August 2005 chromatosis was successively shown to be inherited by autosomal recessive transmission, ${ }^{5}$ mapped to the short arm of chromosome 6 close to the HLA-A locus ${ }^{6,7}$ and associated with mutations of the HFE gene. ${ }^{8,9}$ For much of the 20th century, and especially between 1976 and 1996 when positional cloning studies gained momentum and the presence of an ancestral haplotype of about $6 \mathrm{Mb}$ in size was reported in most patients of European descent, ${ }^{10}$ haemochromatosis was basically considered as a monogenic disorder. This restrictive perception of the disease was reinforced by HFE gene identification since the vast majority of haemochromatosis cases were found to be homozygous for a founder mutation linked to the ancestral haplotype and leading to the substitution of a tyrosine residue for cysteine at position $282(\mathrm{C} 282 \mathrm{Y}) .{ }^{11}$ By analogy with the MHC class I family of molecules, including HLA-A2 with which the HFE protein shares $37 \%$ sequence identity, it was immediately proposed that the predominant mutation in haemochromatosis probands 
Table 1 Classification of haemochromatosis

\begin{tabular}{llllc}
\hline Classification & Gene & Protein & Inheritance & OMIM accession number \\
\hline Haemochromatosis type 1 & HFE & HFE & AR & 235200 \\
Haemochromatosis type 2A (juvenile haemochromatosis) & HJV & Haemojuvelin & AR & $602390-608374$ \\
Haemochromatosis type 2B (juvenile haemochromatosis) & HAMP & Hepcidin & AR & $602390-606464$ \\
Haemochromatosis type 3 & TfR2 & Transferrin receptor 2 & AR & 604250 \\
Haemochromatosis type 4 & SLC40A1 & Ferroportin & AD & 606069 \\
& HFE/HAMP & HFE/Hepcidin & Digenic \\
\hline
\end{tabular}

AR: autosomal recessive; $A D$ : autosomal dominant

OMIM: On-line Mendelian Inheritance in Man (http://www.ncbi.nlm.nih.gov).

prevents the formation of a crucial disulphide bridge and, as a consequence, has an important effect on HFE protein structure. ${ }^{8}$ Its functional impact was demonstrated in iron overload mice carrying an artificially introduced C282Y mutation. ${ }^{12}$

The discovery of the HFE gene and the development of simple tests for C282Y mutation genotyping were important steps in the diagnosis of haemochromatosis and the identification of related individuals at risk of developing iron overload. Once completed by the search for the change in amino acid 63 from histidine to aspartic acid (H63D), a more prevalent substitution albeit associated with a weak structural impact, ${ }^{13}$ and the subsequent scanning of the whole HFE coding region, the cloning of the HFE gene also paved the way for the identification of non-HFE-related forms of haemochromatosis. From 2000 to 2004, these rare conditions, which are of either adult or juvenile onset, were successively related to mutations in the genes that encode transferrin receptor 2 (TFR2), ${ }^{14}$ ferroportin 1 (SLC4OA1), ${ }^{15}$ hepcidin $(H A M P)^{16}$ and haemojuvelin $(H J V) .{ }^{17}$ The description of a digenic mode of inheritance has recently completed our knowledge of the molecular basis of haemochromatosis ${ }^{18,19}$ and, thus, definitively altered the monogenic perception of this old disease (Table 1).

This review will focus on the genetics of haemochromatosis, highlighting recent advances and hypotheses in our understanding of key regulatory mechanisms of iron homeostasis.

\section{Classification of haemochromatosis}

As stated in the Introduction, the term haemochromatosis (synonymous with hereditary or primary haemochromatosis) first referred to the HFE-related historical and most common condition, now called haemochromatosis type 1 , which is characterized by increased duodenal iron absorption and rapid iron release from macrophages. This physiologically abnormal situation leads to the accumulation of iron in the blood compartment (manifested by a rise in serum transferrin saturation) and favours the progressive iron loading of parenchymal cells (witnessed by an increase in concentrations of serum ferritin). Iron tends to be selectively deposited in hepatocytes, but organs like the heart and pancreas are also targeted. More males than females are affected and onset is usually in the fourth decade for men and the fifth for women. At its fully developed stage, iron loading impairs the function of target organs and damages their structure. The clinical consequences of iron overload can be prevented by early diagnosis and treatment with repeated phlebotomies. ${ }^{20}$

Disregarding the onset and incidence of some clinical manifestations, haemochromatosis types 2 and 3 display similar histological and clinical features. Haemochromatosis types $2 \mathrm{~A}$ and $2 \mathrm{~B}$ refer to juvenile autosomal recessive conditions, respectively, associated with mutations in the $H J V$ gene and the HAMP gene. These juvenile conditions are distinguished by greatly accelerated iron accumulation, which affects both sexes and causes clinical symptoms before the age of 30 years. Clinical manifestations are marked by an increased incidence of hypogonadism and cardiomyopathy. ${ }^{21,22}$ Haemochromatosis type 3 refers to another autosomal recessive condition, which is due to mutations in the TFR2 gene and which could be classified as intermediate between the classical adult-type and the two juvenile types. ${ }^{23}$

Finally, haemochromatosis type 4 is related to an adult autosomal dominant iron overload syndrome caused by mutations in the ferroportin 1 gene. As this syndrome displays distinct biochemical, histological and clinical features, it is called 'ferroportin disease' by many authors, ${ }^{24-26}$ a situation that highlights the need for a less confused classification. As suggested by Roetto and Camaschella, ${ }^{25}$ the new respective terms for the disorders could be HFE-related haemochromatosis, TFR2-related haemochromatosis, HAMP- or HJV-related haemochromatosis and ferroportin disease.

\section{Haemochromatosis type 1 - HFE related Predominance of the C282Y homozygous and C282Y/H63D compound heterozygous genotypes in the haemochromatosis patients}

The positional cloning strategy that led to HFE identification was focused on the search for a founder mutation carried by an ancestral haplotype. The founder effect was previously suggested by the increased frequency of the HLA-A3, B7 and HLA-A3, B14 allelic associations in haemochromatosis patients, ${ }^{7}$ and subsequent linkage-disequilibrium studies demonstrated that a large DNA 
segment was identical-by-descent in the vast majority of the affected chromosomes. ${ }^{10}$ From a cohort of 178 patients, Feder et $\mathrm{al}^{8}$ identified the HFE $845 \mathrm{G}>\mathrm{A}$ transition (C282Y) on the ancestral haplotype and showed that this predominant mutation was found in the homozygous state in $83 \%$ of patients. They further found that most of the nonancestral haplotypes carried the $187 \mathrm{C}>\mathrm{G}$ transversion (H63D) and indicated that this second mutation was overrepresented on the chromosomes not affected by the C282Y mutation. Subsequent genotype/phenotype correlation studies confirmed the strong relationship between the C282Y homozygous genotype, found in $64-100 \%$ of patients, and typical haemochromatosis phenotypes. They also revealed that the $\mathrm{C} 282 \mathrm{Y} / \mathrm{H} 63 \mathrm{D}$ compound heterozygous genotype accounted for $74-100 \%$ of the non-C282Y homozygous patients and was associated with milder iron overload phenotypes. ${ }^{27}$

Despite an estimated frequency of $2 \%$ in European countries, the H63D homozygous genotype is rarely associated with an iron-loading condition. ${ }^{11,28}$ Moreover, the H63D amino-acid change has little effect on HFE protein structure and is not expected to produce a significant loss-of-function. ${ }^{13}$ These observations support the idea that to be causative the frequent H63D variant requires the presence of an additional risk factor, such as a trans-C282Y mutation or excessive alcohol intake. ${ }^{29}$

\section{$282 \mathrm{Y}$ and $63 \mathrm{D}$ allele frequencies and related theories} The prevalence of the $\mathrm{C} 282 \mathrm{Y}$ heterozygous genotype in European populations is about 1 in $11(9.2 \%)$, but is not homogeneous and decreases from the north-west to the south-east, which is consistent with the disease distribution. ${ }^{30}$ The highest frequencies have thus been reported in Ireland (28.4), ${ }^{31}$ Brittany (17.4; unpublished result obtained from a sample of 796 subjects) and Wales (16.6), ${ }^{32}$ whereas the lowest frequencies have been observed in Italy (3.2) and Greece (2.6). ${ }^{11}$ These observations have often been related to the existence of a founder Celtic effect, ${ }^{27,33}$ but a link with the Viking conquests and migrations has also been suggested. ${ }^{33}$ Much later, successive migrations from the western parts of Europe have introduced the C282Y mutation in white populations of North America, New Zealand and Australia., ${ }^{4,27}$ On the other hand, the fact that the ancestral haplotype is about $6 \mathrm{Mb}$ in size suggests that the $\mathrm{C} 282 \mathrm{Y}$ mutation arose in the past 2000 years. ${ }^{34}$ If so, its current frequency is due to positive selection. A pressure mode is not easy to define as it can be single or multiple and may or may not still be effective. However, in case of the HFE gene, two hypotheses have been proposed. The first is particularly disputed, ${ }^{35}$ and is based on resistance to iron deficiency and a subsequent positive effect on the reproduction of young C282Y heterozygous women in ancient times, when dietary iron was scarcer. ${ }^{36}$ The second hypothesis adduces a protective effect against some pathological agent. It could be related either to the use of the HFE protein as a cell surface receptor by some infectious agent ${ }^{34}$ or to the relative iron deficiency that occurs with the C282Y mutation, and posits a possible protection against a number of virulent species of bacteria that multiply mainly in rich-iron macrophages. ${ }^{37}$

By contrast, the $\mathrm{H} 63 \mathrm{D}$ variant is older than $\mathrm{C} 282 \mathrm{Y}$ and is carried on a greater diversity of haplotypes. Its allele frequency is more than $5 \%$ in the Celtic population as well as in other Caucasian, Asian, Indian and African populations, and is particularly high in Southern-European regions like Spain (up to 32.3\%). ${ }^{11} \mathrm{H} 63 \mathrm{D}$ may have arisen spontaneously in several parts of the world and its transmittance may have also been favoured through selective advantage. According to this assumption, Rochette et $\mathrm{al}^{34}$ noted that the H63D amino-acid change occurs in the HFE $\alpha 2$-domain, an extra-membrane region that might be implicated in interactions with infectious agents.

\section{Other HFE genotypes related to iron overload phenotypes}

Depending on the population studied, between 4 and 35\% of cases presenting with haemochromatosis phenotypes are C282Y or H63D heterozygotes, or lack both C282Y and H63D. ${ }^{38}$ The HFE coding region from some of these patients has been studied, and 19 non-neutral novel variations have now been identified. With few exceptions, these variations occur in tandem with trans-C282Y mutations and are private (Figure 1).

S65C missense mutation The $193 \mathrm{~A}>\mathrm{T}$ transversion, which leads to the serine 65 to cysteine substitution (S65C), displays a frequency ranging from 1.6 to $5.5 \%$ on Caucasian chromosomes. ${ }^{39}$ This mutation produces no evident effect on the HFE protein structure, but we and others have found that it is significantly enriched on affected chromosomes that carry neither the $\mathrm{C} 282 \mathrm{Y}$ nor the H63D mutation. Moreover, it is associated with mild iron overload phenotypes when inherited with the predominant C282Y mutation in the compound heterozygous state. ${ }^{40-44}$ As with the H63D mutation, the S65C mutation should be considered as a risk factor rather than as a causative mutation, and either included in routine screening tests or genotyped when the systematic search for the two main haemochromatosis mutations is found to be insufficient.

E168X and W169X nonsense mutations The case of the E168X and W169X variations can also be highlighted since they have been found in the compound heterozygous state with $\mathrm{C} 282 \mathrm{Y}$ in haemochromatosis patients from two northern regions of Italy more frequently than the H63D mutation (respectively, in 25 and $8.4 \%$ of patients). ${ }^{45}$ This situation is representative of founder populations, in which the molecular testing strategy must be adapted.

HFE private mutations The other 16 uncommon HFE mutations are private and have mostly been described in 


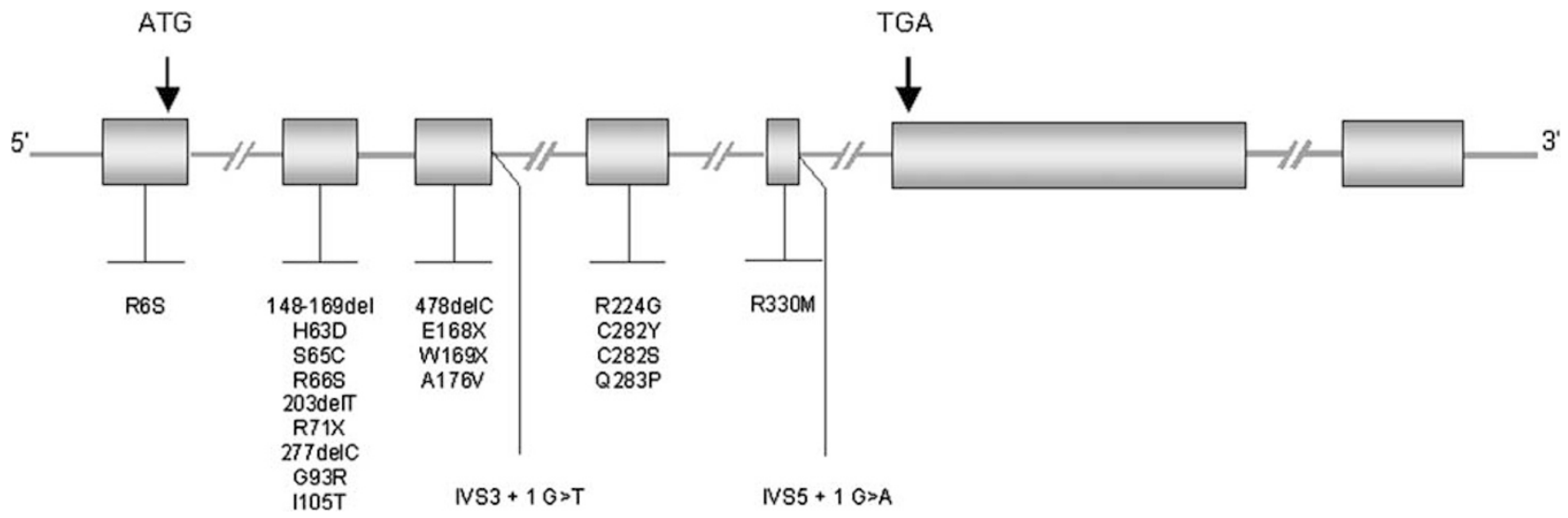

Figure 1 Schematic representation of mutations in the HFE gene.

single patients or families. As genotype/phenotype correlation studies from unrelated subjects are unfeasible, the implication of some of the reported variations in iron overload phenotypes is not evident. A practical approach to overcoming this problem is to consider the nature of the variations and their expected functional consequences. According to this strategy, two groups of mutations can be distinguished. The first is composed of one nonsense (R71X), four frameshift (148-169del, 203delT, 277delC, 478delC) and two splice-site mutations (IVS3 $+1 \mathrm{G}>\mathrm{T}$, IVS5 $+1 \mathrm{G}>\mathrm{A}$ ). These mutations produce abnormal HFE mRNAs and/or highly modified or truncated HFE proteins. Even if they have been detected just once, these mutations may be useful for the molecular diagnosis of haemochromatosis patients and the identification of related individuals at risk of developing iron overload. The second group of private $H F E$ variations is composed of nine missense mutations. The C282S variation, as the main hereditary haemochromatosis mutation, should be considered a causative allele. ${ }^{46}$ We successively demonstrated that the Q283P amino-acid change, which introduces a proline in a central $\beta$-strand position and is adjacent to cysteine 282, significantly damages the 3D structure of the HFE $\alpha-3$ domain $^{47}$ and leads to functional consequences similar to those described for the C282Y mutation. ${ }^{48}$ The R66S mutation might also be considered for haemochromatosis diagnosis, since the change of arginine 66 to glutamic acid (R66E) has been found to have a functional incidence: it reduces the capacity of HFE to inhibit iron release from reticuloendothelial cells. ${ }^{49}$ In the absence of functional characterization, implication of the other six rare HFE missense mutations found in mild to severe haemochromatosis phenotypes must be considered with caution.

Prevalence and penetrance of the C282Y homozygous genotype in the perception of haemochromatosis

A concise historical perspective helps to explain why haemochromatosis was deemed rare, then considered as the most common autosomal recessive disorder in populations of Northern European descent, and now again viewed as rare. When haemochromatosis was classed as an inborn error of metabolism by Sheldon in 1935, the disease was expected to be rare. ${ }^{3}$ In a review published in 1955, Finch and Finch $^{50}$ reported that haemochromatosis was responsible for only one per 7000 hospital deaths and one per 20000 hospitalizations in the United States. In the 1980s, the use of biochemical measurements, especially of transferrin saturation, which was presented as a valuable phenotypic marker in detection of subjects homozygous for the ancestral haemochromatosis mutation (not yet identified as the $\mathrm{C} 282 \mathrm{Y}$ substitution), ${ }^{51}$ challenged clinically based evaluations and led to estimation of a novel prevalence between three and eight per 1000 individuals of Northern European origin. ${ }^{52-54}$ The biochemical prevalence of haemochromatosis was commonly cited in the literature until the identification of the HFE gene and the description of the C282Y homozygous genotype in five of 1000 individuals from identical populations. ${ }^{11,27,34}$ Therefore, a relationship was revealed between genetic and biochemical prevalence, albeit mainly when considering transferrin saturation rather than ferritin concentrations. By contrast, the estimated frequency of C282Y homozygous individuals in Northern European populations has shown that affected individuals remain clinically untroubled by haemochromatosis. This situation was not apparent from initial genotype/phenotype correlation studies since they were biased by a strong selection of patients, mostly recruited because of clinical features.

In the past few years, several large population studies have addressed the question of the penetrance of the C282Y homozygous genotype (ie the proportion of the $\mathrm{C} 282 \mathrm{Y}$ homozygous individuals who exhibit an iron overload phenotype). This question calls for a uniform approach (regarding the recruitment of individuals and the selection of biochemical, treatment-based, histological or clinical criteria), but the idea is emerging that a majority of 
C282Y homozygous subjects will present abnormal iron parameters, ${ }^{55}$ whereas only a small number will manifest clinical features. ${ }^{56-58}$ The influence of environmental components, such as excessive alcohol consumption, ${ }^{56,59,60}$ surely explains one part of this phenotypical heterogeneity. The influence of epigenetic mechanisms or of modifier genes is an attractive additional explanation, and has been the subject of much recent discussion in the literature. ${ }^{18,19,61-64}$ From a cohort of 392 C282Y homozygotes, we found one male and four female carriers of an additional HAMP mutation in the heterozygous state. We found that iron indices of these five patients were among the most elevated of the cohort and, using a comparative study with $\mathrm{C} 282 \mathrm{Y}$ females of similar age range, that the transferrin saturation levels of the four females were also significantly increased. Combined with a previous report by Merryweather-Clark et al, ${ }^{19}$ along with the concomitant demonstration by Nicolas et $a l^{62}$ of an increased hepatic iron loading in $\mathrm{HFE}^{-1-}$ mice with an additional HAMPdeficient allele, these data allowed us to propose that, even though they are not frequent, HAMP mutations could explain one part of the C282Y homozygous-related phenotypic heterogeneity by accentuating the iron burden. In the same cohort of $\mathrm{C} 282 \mathrm{Y}$ homozygous patients, we more recently identified nine patients (six males and three females) heterozygous for an additional mutation in the second juvenile haemochromatosis-related gene, namely $H J V$. As reported in the case of the HAMP gene, the iron indices of eight patients appeared to be more severe than those observed in C282Y homozygous patients of identical sex and similar age ranges. The mean serum ferritin concentration of the six males with a $H J V$ mutation was significantly higher than that of $\mathrm{C} 282 \mathrm{Y}$ homozygous males without an additional mutation. These observations implicate another haemochromatosis gene as a possible modifier of HFE C282Y homozygous expression.

The search for other modifier genes is crucial as it could enable us to distinguish more precisely those $\mathrm{C} 282 \mathrm{Y}$ homozygous patients at increased risk of developing severe iron overload and, consequently, clinical complications. In addition to our two candidate gene approaches, others have been used. They have led to negative conclusions except for those highlighting a possible association between increased iron loading and either the haptoglobin type 2-2 or the $16189 \mathrm{~T}>\mathrm{C}$ mitochondrial DNA polymorphisms. ${ }^{35,56,65}$ An alternative to the candidate gene approach is the use of knockout mouse models of haemochromatosis. Bensaid et al ${ }^{63}$ have recently produced mice from an F2 intercross between two HFE-deficient strains that greatly differ in their propensity to develop hepatic iron loading. Through a linkage analysis study, they identified four loci that independently co-segregated with severity of the iron loading and were found to contain several iron metabolism genes. Analysis of these genes will probably support the identification of novel modifiers. As emphasized by the authors, further positive results may also come from the study of the syntenic chromosomal regions in humans.

\section{Haemochromatosis types $2 \mathrm{~A}$ and $2 \mathrm{~B}-\mathrm{HJV}$ - and HAMP-related}

Juvenile haemochromatosis differs from typical HFE-related haemochromatosis in that it affects both sexes equally, is linked to a faster iron deposition in parenchymal cells (with an iron distribution similar to that observed in the case of HFE), causes clinical symptoms in the second and third decades of life and, although liver dysfunction is also part of the syndrome, is associated with a more frequent presentation of hypogonadism and cardiomyopathies. In the absence of treatment, juvenile haemochromatosis patients may succumb to heart failure before the age of 30 years. ${ }^{21,22}$

\section{Molecular basis}

Juvenile haemochromatosis is genetically heterogeneous, as it can be associated with mutations in two genes. The main locus was mapped to 1q21 by Roetto et al $l^{66}$ in 1999. Subsequent cloning of the causative gene proved difficult because of several gaps in the genome assembly of the pericentromeric 1q region and the combined exclusion of candidates implicated in iron metabolism. In all, 5 years passed before Papanikolaou et $a^{17}$ identified the $H J V$ gene (originally called HFE2), through the linkage analysis of 12 unrelated families predominantly of Greek origin, but also of Canadian or French descent. The authors identified six different mutations with one, the G320V substitution, observed in the homozygous or compound heterozygous state in $80 \%(15 / 19)$ of the patients. This predominant mutation was reported in some of six additional studies, based on a total of 43 novel families from Southeast USA, Italy, Saguenay-Lac-Saint Jean (Canada - Quebec), England, Albania, Australia, France, Germany, Slovakia, Croatia, Romania and China. It was found to be particularly prevalent in Saguenay-Lac-Saint Jean, where 18 homozygous patients were detected, while patients of different genetic backgrounds have permitted the identification of 23 novel mutations, thus highlighting marked allele heterogeneity ${ }^{67-72}$ (Figure 2).

As soon as the main gene responsible for juvenile haemochromatosis was mapped to 1q21, it became clear that some families were linked to a rarer morbid locus. Roetto et $\mathrm{al}^{16}$ took advantage of the identification of HAMP as a key regulator of iron haemostasis and identified two mutations (93delG and R56X) in its coding gene, HAMP (19q13). This positive result, exclusively based on a gene candidate approach and the study of only two pedigrees from Italy and Greece, was confirmed by the report of three novel mutations in four other unrelated families: the C70R and C78T substitutions, which disrupt one of four 


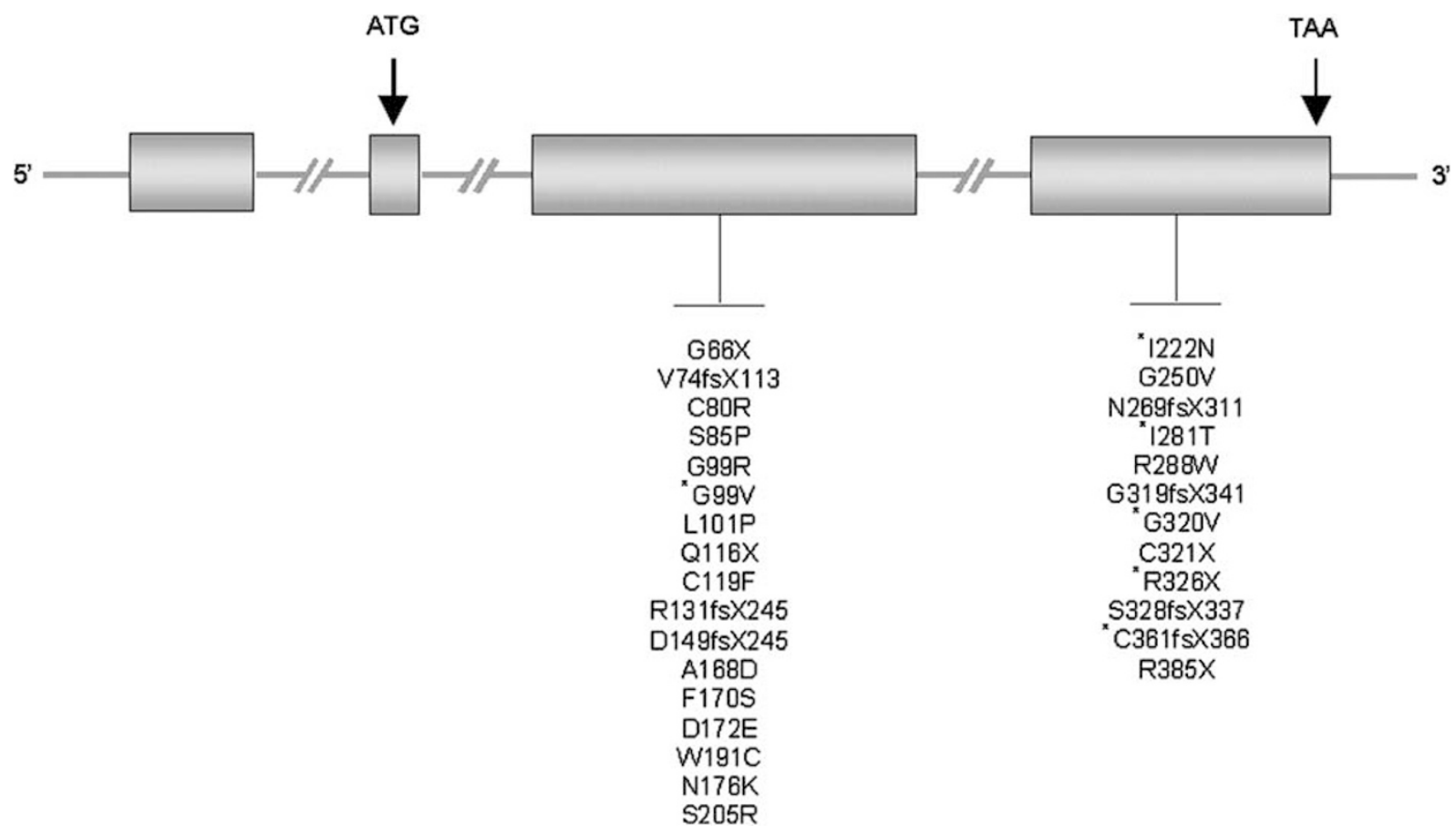

Figure 2 Schematic representation of mutations in the HJV gene. The first six reported mutations, including the predominant G320V amino-acid change, are marked with asterisks.

disulphide bridges that are critical for the $3 \mathrm{D}$ hairpin structure of the HAMP peptide, ${ }^{73-75}$ and the $5^{\prime}-\mathrm{UTR}+14$ $\mathrm{G}>\mathrm{A}$ transition, which creates a new AUG codon. This premature start codon induces a shift of the reading frame and is further believed to prevent the synthesis of normal HAMP (Figure 3). ${ }^{76}$

\section{Connection with our current knowledge of iron homeostasis}

The discovery of HAMP has shown that the liver plays a central role in determining the amounts of iron that must be mobilized from macrophages (where most of the iron available in the body is recycling from senescent blood cells), enterocytes (where iron is absorbed from the diet to compensate daily losses or more pronounced iron deficiencies) and hepatocytes (where iron is stored and can be released at times of increased demand) to meet the body's needs.

HAMP was first identified as an antimicrobial peptide, secreted in urine and synthesized in the liver. ${ }^{77,78}$ The first link between HAMP and iron metabolism arose from the study of Pigeon et al, ${ }^{79}$ who showed that the amount of HAMP mRNA increases dose-dependently in the liver of experimentally or spontaneously iron-overloaded mice. Then, Nicolas et al ${ }^{80,81}$ showed that $H A M P$-deficient mice develop a human-like haemochromatosis phenotype (with iron deposition in the liver and pancreas, while iron deficiency is apparent in the spleen macrophages), whereas mice overexpressing $H A M P$ under the control of a liver- specific promoter are severely anaemic and die shortly after birth unless supplemented by parenteral but not enteral iron. These early observations in transgenic mice led to the conclusion that HAMP was a key negative regulator of dietary iron absorption, iron transport across the placenta and iron release from macrophages.

Several in vitro studies have confirmed the relationship between the level of HAMP synthesis in hepatocytes and the need either to increase or decrease iron availability regarding syndromes such as iron loading, anaemia (related to inflammation syndromes) and hypoxia. They have also deepened our understanding of iron homeostasis, while uncovering novel cellular mechanisms. ${ }^{82-85}$ There is no doubt that one of the most important of these mechanisms is associated with HAMP's capacity to bind ferroportin and cause its degradation, since ferroportin is the only known transporter that mediates release of iron from macrophages, enterocytes and hepatocytes. ${ }^{86}$ In the enterocytes, this novel discovery allows the suggestion that HAMP targets ferroportin on the basolateral membrane, blocking the unique pathway for egress of iron from the diet and, thus, causing an intracellular iron excess. In turn, this intracellular iron excess will be responsive to the known downregulation of genes such as DMT1 (which encodes a duodenal iron transporter) and $D c y t B$ (which encodes a duodenal ferric reductase), thus reducing apical iron uptake from the diet, but also such as SLC4OA1 itself, thus increasing the negative effect on the basolateral membrane. ${ }^{82,85}$ 

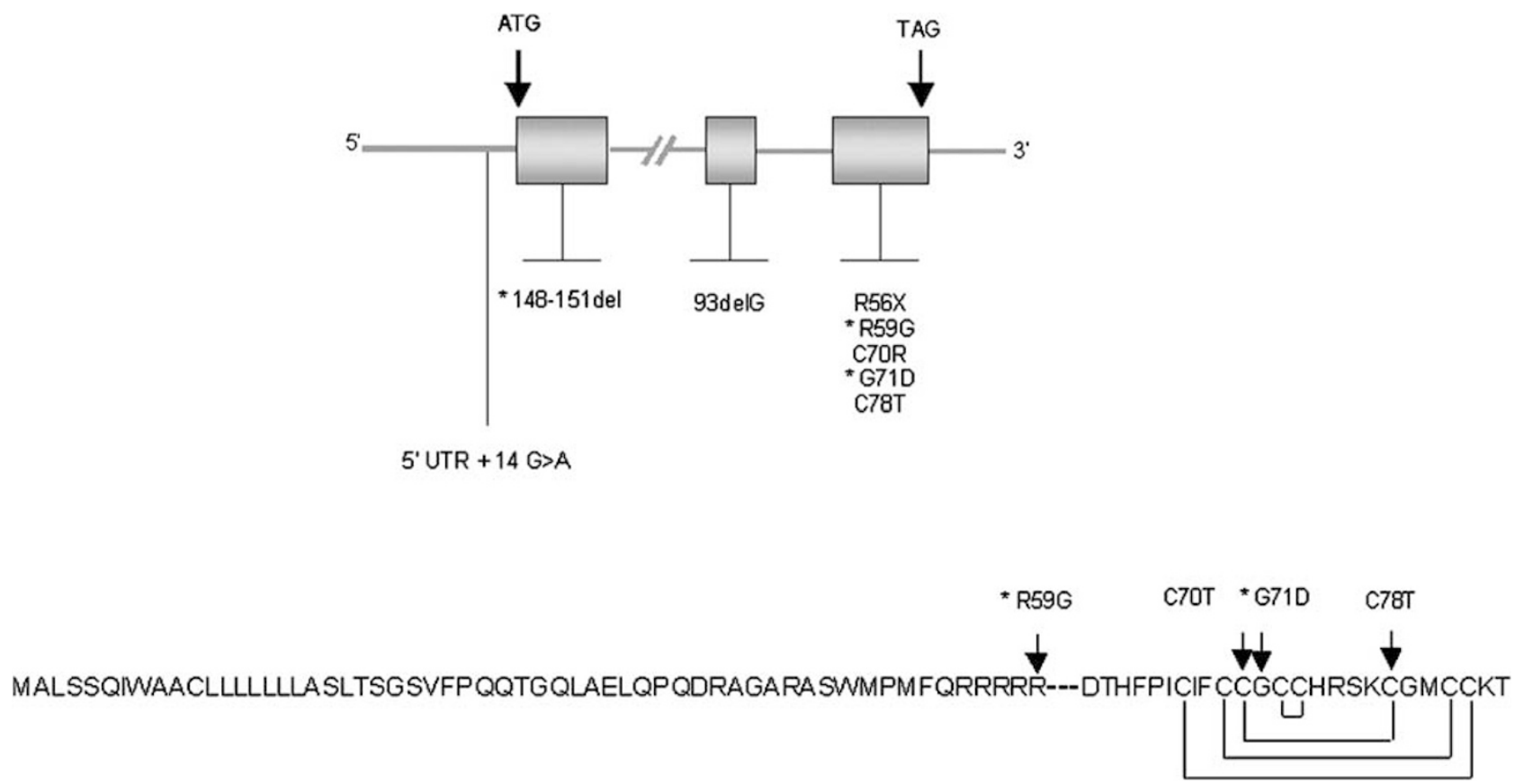

Figure 3 Schematic representation of mutations in the HAMP gene. Mutations related to HFE/HAMP digenic inheritances are marked with an asterisk. The 84-amino-acid sequence of pro-HAMP is also presented. The mature peptide is divided from the penta-arginine basic domain (-); the eight cysteines are linked with their bonds. Positions of the four reported missense mutations are indicated.

Concordant studies have also shown that the haemochromatosis gene products HFE, TFR2 and HJV are required for HAMP production that correlates with the body's iron status. In fact, expression of HAMP mRNA in the liver and/ or assay of HAMP in the urine have been found to be inadequate (low or very low) regarding iron overload phenotypes of either genetic mice models or patients homozygous for mutations in HFE, TFR2 and HJV. ${ }^{17,87-90}$ Further studies are needed to clarify these observations but, taking into account the common expression of the three proteins in hepatocytes, it is tempting to propose that HFE, TFR2 and HJV act as modulators of HAMP transcription in response to iron and, thus, that the four haemochromatosis-related proteins are implicated in a common pathway. This suggestion does not exclude the existence of more independent functions for each of the proteins considered, but it establishes a physiological basis underpinning the existence of the digenic mode of inheritance in haemochromatosis, hitherto related to either the HFE/TFR2 or HFE/HAMP pair, as well as the modifier effects produced by the presence of a heterozygous mutation in one of the two juvenile haemochromatosis genes in patients already homozygous for the HFE C282Y mutation. ${ }^{18,62,64}$

\section{Haemochromatosis type 3 - TFR2-related Molecular basis}

With the identification of the TFR2 gene as causative in 2000, haemochromatosis type 3 was the first non-HFE- related form for which a molecular diagnosis was possible. The first paper was published by Camaschella et al, ${ }^{14}$ who identified the homozygous Y250X nonsense mutation in six patients from two unrelated Sicilian families. The causality of this mutation was confirmed by the description of an iron overload phenotype, with features comparable to those of the human disease, in mice with a targeted (on the corresponding Y245 amino acid) and identical mutagenesis (Y245X). ${ }^{91}$

So far eight novel mutations have been identified in the TFR2 gene (Figure 4). These mutations have been detected in south European pedigrees, with an Italian specificity, but also in patients of French and Japanese extraction. ${ }^{23,92-97}$ Identification of the AVAQ 594-597del (three siblings), L490R (one case) and V561X (one case) mutations in Japanese patients is notable since, in contrast to Caucasian populations, haemochromatosis is a rare genetic disease in Asian populations. ${ }^{92,97}$

\section{Is TFR2-related haemochromatosis intermediate} between the adult-HFE and the two juvenile forms? As first shown by Girelli et al ${ }^{94}$ (in 13 patients homozygous for a TFR2 mutation), despite the observation of young patients, the iron overloads attributable to haemochromatosis type 3 are variable and distinct from those of juvenile haemochromatosis. Based on the review of the 23 cases reported in the literature until 2004, we have, however, suggested that haemochromatosis type 3 is a syndrome 


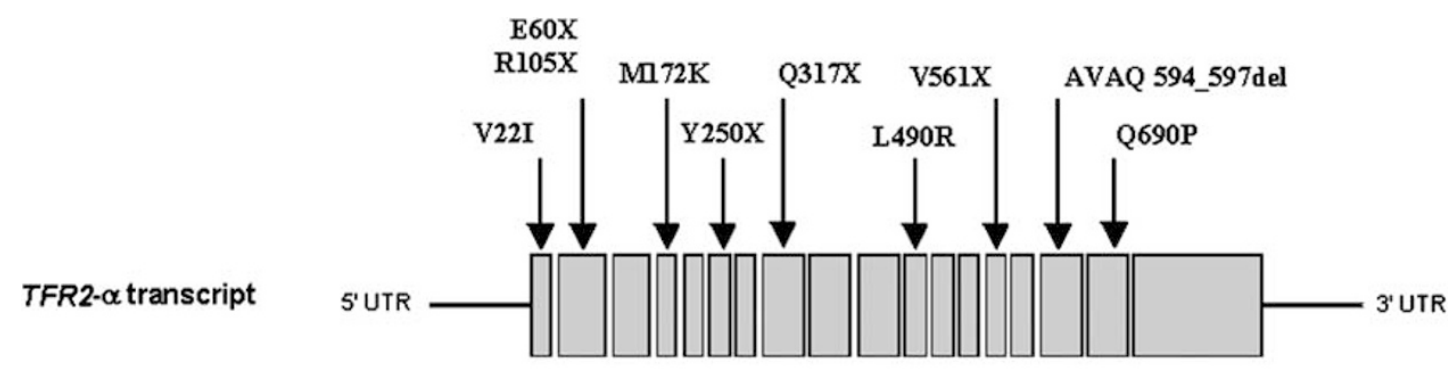

TFR2 -8 transcript

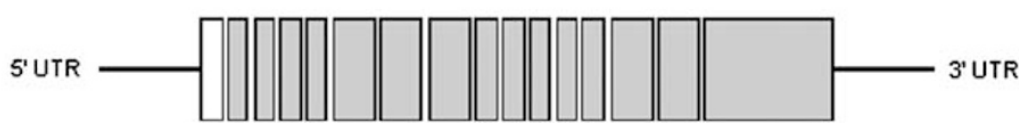

Figure 4 Schematic structure of the TFR2 gene transcripts. Compared with the TFR2- $\alpha$ transcript, which contains 18 exons (grey box), the TFR2- $\beta$ transcript lacks exons $1-3$ and conserves the last 142 noncoding bases of intron 3 (white box). Positions of the 10 reported mutations are indicated.

intermediate between typical adult-onset $H F E$-related haemochromatosis and the two juvenile forms. ${ }^{23}$

This suggestion leads to the view that the biochemical and clinical courses of iron overload in patients homozygous for TFR2 are more rapid than that usually reported in HFE-related patients. Consistent with this idea, we showed that the age at diagnosis was significantly lower in the 23 TFR2-related homozygous patients than among two cohorts of $421 \mathrm{C} 282 \mathrm{Y}$ homozygous patients $(P=0.0002)$ and $96 \mathrm{C} 282 \mathrm{Y} / \mathrm{H} 63 \mathrm{D}$ compound heterozygous patients $(P=0.0001)$, and further observed that evidence of biochemical iron overload was detected in four TFR2-related females and five TFR2-related males before the age of 30 years. Clinical features, including arthralgia (two of four), hypogonadism (two of four), skin pigmentation (one of four) and cirrhosis (one of four), were noted in four of the nine.

Very recently, Pietrangelo et $a l^{96}$ reported the case of a pair of Italian sibs (of opposite sexes) where juvenile haemochromatosis resulted from the synergic effect of mutations in TFR2 (Q317X homozygosity) and HFE (C282Y/H63D compound heterozygosity), rather than from homozygous or compound heterozygous mutations in the HJV or HAMP gene. The authors have proposed that the TFR2 and HFE genotypes, considered singly, would be expected to produce no more than the adult onset typically seen with the haemochromatosis type 1 and 3 forms, whereas their combination may be sufficient to produce a juvenile haemochromatosis phenotype. The concomitant observation of a younger brother homozygous for the nonsense TFR2 mutation, but presenting with a less severe iron overload phenotype, was used to support this assumption. Without disregarding the explanation advanced by Pietrangelo et al, and because the younger brother was found to have raised iron values (transferrin saturation of $100 \%$; serum ferritin concentration of $955 \mu \mathrm{g} / \mathrm{l}$ ) along with skin pigmentation and hepatic iron overload (hepatic iron index of 2.9) at 21 years of age, one may also consider this new report as another indication that TFR2related haemochromatosis is intermediate between classical adult-onset HFE and the two juvenile forms. Recent identification of the L490R and V561X mutations in Japanese patients with haemochromatosis manifesting at middle age, respectively, at 41 and 58 years old, could serve to counterbalance the Italian observation. However, it should be noted that the V561X patient was diagnosed with the historical triad of cirrhosis, diabetes mellitus and skin pigmentation along with congestive heart failure, while cirrhotic liver histology and diabetes were noted in the younger L490R homozygous patients. ${ }^{97}$

The iron metabolism function of TFR2 has yet to be clearly defined, but there are cumulative arguments to suggest that this second receptor for transferrin acts as a liver sensor of circulating iron and thereby plays a significant role in HAMP expression.

The TFR2 gene encodes two transcripts: a $2.9 \mathrm{~kb}$ isoform, called TFR2- $\alpha$, and a $2.5 \mathrm{~kb}$ isoform, called TFR2- $\beta$, which lacks exons $1-3$ and conserves the last 142 noncoding bases of intron 3 (Figure 4 ). Whereas the TFR2- $\beta$ transcript is weakly expressed in various tissues, TFR2- $\alpha$ is predominantly transcribed in hepatocytes, ${ }^{98,99}$ where HAMP expression is limited. ${ }^{100}$ Moreover, the TFR2- $\alpha$ form encodes a type II membrane protein that shares $45 \%$ identity and $66 \%$ similarity in its extracellular domain with the transferrin receptor (TFR1). ${ }^{98}$ This new TfR-like receptor has a lower affinity for holotransferrin, ${ }^{101}$ but its translation is not downregulated when the cellular iron content is high ${ }^{99,101}$ (in comparison with the TFR1 transcript, the $3^{\prime}$ untranslated region of the TFR2- $\alpha$ mRNA lacks iron responsive elements). In 2002, the latter findings allowed 
Fleming et $a l^{91}$ to suggest that the TFR2- $\alpha$ receptor mediates hepatocyte transferrin-bound iron uptake, which is dependent on plasma transferrin saturation levels. In turn, the hepatocyte iron content would correlate HAMP synthesis with the body's iron needs. More recent studies still argue for a TFR2-piloted sensory role in the liver, ${ }^{84,89,90}$ most notably those that have demonstrated that TFR2 is stabilized in vitro in the presence of diferric transferrin. ${ }^{102,103}$

In future, data elucidating the mechanism(s) by which HFE, TFR2 and HJV influence HAMP liver expression would aid the classification of haemochromatosis according to age at onset.

\section{Haemochromatosis type IV - ferroportin disease Molecular basis}

The existence of an adult, autosomal, dominant primary iron overload, soon regarded as an atypical form of haemochromatosis, was based on the description of Melanesian (Solomon Islands), ${ }^{104}$ Italian $^{105}$ and Dutch ${ }^{15}$ pedigrees. Concomitant genome-wide screens and the search for iron metabolism genes in the identified morbid regions (on 2q32) resulted in successive reports of the SLC40A1 heterozygous $430 \mathrm{~A}>\mathrm{C}(\mathrm{N} 144 \mathrm{H})$ and $230 \mathrm{C}>\mathrm{A}$ (A77D) transversions, respectively, in Dutch ${ }^{15}$ and Italian patients. ${ }^{106}$ The study of the Melanesian pedigree is as yet incomplete, but the description of the $431 \mathrm{~A}>\mathrm{C}$ transversion (N144T) in an iron overload patient of MelanesianSolomon Island extraction suggests that it was also related to ferroportin disease. ${ }^{107}$

In all, 12 other mutations have been reported in the SLC4OA1 gene (Figure 5). As the three mutations referenced above are at variance with the distribution of the $\mathrm{C} 282 \mathrm{Y}$ HFE mutation, they have been identified in patients with distinct genetic backgrounds. A common mutation, the Val 162 deletion, has particularly been found in unrelated families from the United Kingdom, Australia, Italy and Greece. ${ }^{108-111}$ The other SLC4OA1 mutations are private, with the exception of the Q248H substitution, which has been detected at high frequency in some populations of African descent, but for which causality is a matter of debate. $^{112-115}$

Proposal of two functional groups in the classification of ferroportin mutations

The 15 reported mutations span the entire primary sequence of ferroportin. However, considering consensus predicted structures with the presence of nine or more transmembrane domains, 12 mutations (from Y64N to D270V) cluster in domains 1-4, and nine of them localize to the external face of the protein. ${ }^{109,116}$ Taking into account the cellular iron export activity of ferroportin and its strong expression in liver macrophages (Kupffer cells) and duodenal enterocytes, ${ }^{117-119}$ it was first hypothesized that ferroportin interacts with caeruloplasmin (on the membrane of macrophages) and hephaestin (on the basolateral membrane of enterocytes), or hephaestin alone (which has recently been found to be expressed on the membrane of both macrophages and enterocytes ${ }^{100}$ ), to generate ferroxidase activity and provide $\mathrm{Fe}^{3+}$ for circulating transferrin. Without disregarding this complementation model, ${ }^{120}$ and pending detailed analysis of the HAMP-ferroportin interaction, the demonstration by Nemeth et $\mathrm{l}^{86}$ that HAMP negatively regulates ferroportin transporters on the surface of cultured cells has opened the way to characterization of some ferroportin mutants and clearer pathophysiological explanations.

In fact, different phenotypic presentations have been noted in patients with SLC4OA1 mutations, mainly distinguished by the absence or presence of increased transferrin saturation levels and the existence or otherwise of a predominant iron deposition in Kupffer cells. Further investigations may help to explain this phenotypic heterogeneity, in particular the search for modifier factors, but the very recent studies of Schimanski et al ${ }^{115}$ have supplied some very important information. These authors first showed that the 77D, V162del and 490D ferroportin protein displayed a greatly reduced capacity to reach the

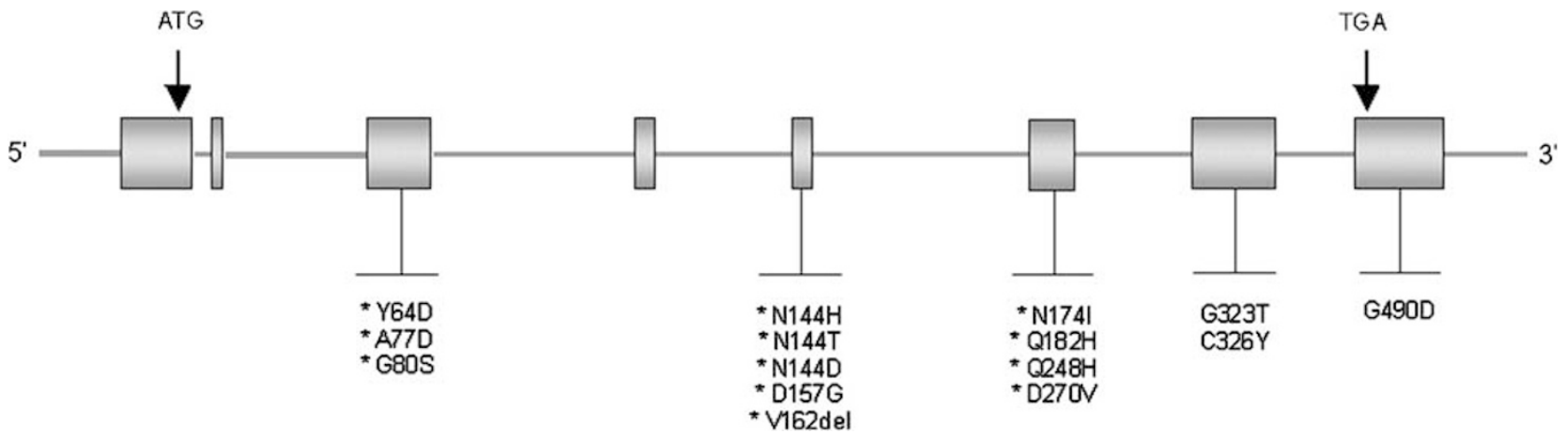

Figure 5 Schematic representation of mutations in the SCL4OA1 gene. Mutations that are expected to cluster in domains 1-4 are marked with asterisks. 
cell surface and permit iron export. In a second study, they found that the $64 \mathrm{~N}, 144 \mathrm{D}, 144 \mathrm{H}$ and $326 \mathrm{Y}$ mutated proteins, which retain cell surface expression and export function, were resistant to inhibition by HAMP. The authors also reviewed the literature and confirmed that the clinical features of haemochromatosis patients carrying the 77D, V162del or 490D mutations are distinct from those carrying the Y64N, N144D, N144H and C326Y mutations, most notably in terms of higher transferrin saturation. ${ }^{121}$

The predominant iron loading of liver macrophages, in contrast to hepatocytes in the HFE haemochromatosis form, with the manifestation of high-serum ferritin concentrations contrasting with normal or slightly elevated transferrin saturation, is the characteristic phenotype of ferroportin disease. ${ }^{24}$ It has been reported for the main V162del mutation and to a lesser extent for the older A77D mutation, which has been associated with an age-dependent rise in transferrin saturation. These loss-of-function mutations do not impede the action of wild-type ferroportin in vitro ${ }^{115}$ and may cause the disease by haploinsufficiency, a model consistent with the autosomal dominant trait of the disease and first suggested by Montosi et al. ${ }^{106}$ The model is related to a more pronounced effect of the mutation considered on iron recycling from senescent erythrocytes by macrophages, which normally supply $\sim 20-30 \mathrm{mg}$ of iron per day, than on absorption of dietary iron by enterocytes, which normally supply $\sim 1 \mathrm{mg}$ of iron per day. ${ }^{122}$ In that case, iron retention by macrophages leads to accumulation of iron in the tissue, which explains the high-serum ferritin levels, and reduces the serum iron available for erythropoiesis, which explains the low transferrin saturation. This negative situation may be responsible for occasional anaemia (observed in patients with intolerance to phlebotomy) and is expected to induce a compensatory mechanism, ordered by the haematopoietic system and leading to upregulation of dietary iron uptake. ${ }^{106,115}$ It should, however, be noted that this compensatory mechanism is at odds with the recent finding of dramatically increased urinary HAMP in two patients heterozygous for the main V162del mutation ${ }^{123}$ and, therefore, the loss-of-function model suggested for some ferroportin mutants needs to be completed.

On the other hand, mutations which resist HAMP regulation in vitro are associated with iron overload conditions less restricted to iron deposition in the Kupffer cells, and are usually marked by a transferrin saturation increase. Shimansky et al particularly focused on the Y64N mutant, reported in individuals displaying iron deposition in hepatocytes and Kupffer cells, ${ }^{124}$ the C326Y and the C326S mutant, which was associated with a predominant iron overload in hepatocytes, ${ }^{125}$ and those affecting asparagine 144 (N144H, D or T), for which iron deposition was either in hepatocytes or had a reticuloendothelial distribution. ${ }^{107,126,127}$ They found a strong correlation between mutations that completely abolish HAMP sensitivity (Y64N and C326S) and high transferrin saturation and, in contrast, between mutations that partially impede HAMP regulation (N144D and $\mathrm{N} 144 \mathrm{H}$ ) and the possibility of keeping transferrin saturation in the normal range. They concluded that HAMP-resistant ferroportin transporters may be associated with a greater flow of iron through the erythrocyte iron-recycling pathway, as well as with increased iron absorption. In that case, the existence of an iron overload in the blood compartment, as observed in typical forms of haemochromatosis, may be related to a better tolerance of phlebotomy. The N144H and N144D mutations, which are associated with less severe dysfunction and with more apparent intra-familial phenotypic heterogeneity, ${ }^{107,127,128}$ may be representative of the influence of additional modifying factors.

\section{HFE/HAMP digenic inheritance in haemochromatosis} At almost the same period, we and others proposed that in some cases a digenic model of inheritance may be responsible for iron overload phenotypes. MerryweatherClarke et $a l^{19}$ first described the association between a juvenile-like haemochromatosis condition and the presence of the C282Y heterozygous mutation in HFE along with a novel frameshift heterozygous deletion in HAMP (148-151del ATGG, which removes methionine at position 50 and the first nucleotide of intron 2). In a second pedigree, they described the coinheritance of the HFE C282Y and HAMP G71D heterozygous missense mutations in a 65 -year-old patient, identified by screening his son (found to be homozygous for the C282Y mutation and heterozygous for the HAMP G71D one), who presented with elevated serum ferritin. The G71D substitution, which was detected in control chromosomes with a $0.3 \%$ allele frequency, was not considered as a highly deleterious mutation. The authors, however, noted that this substitution leads to a change from a neutral amino acid to an acidic residue between two of eight structural cysteines, a modification expected to affect folding of the HAMP peptide and reduce its activity (Figure 3 ). We agreed with this assumption when presenting the cases of four unrelated iron overload patients, firstly identified as heterozygous for the C282Y, H63D or S65C HFE mutations and secondly found to be carriers of either the G71D (one H63D heterozygous patient) or the novel R59G missense mutation in HAMP (one C282Y and two S65C heterozygous patients). We correlated the R59G amino-acid change, which occurs at the critical position for activity of prohormone convertases in a penta-arginine basic domain (residue 55-59), with a preventive effect on production of the 25-amino-acid mature HAMP from the 84-amino-acid pro-HAMP. ${ }^{18}$

Although the digenic model of inheritance has been demonstrated in many other genetic disorders, ${ }^{129}$ it can be 
related to the involvement of the HFE and HAMP gene products in a common pathway ${ }^{18,62,84}$ and is also consistent with the synergic effect proposed by Pietrangelo et $a l^{96}$ to implicate HFE and TFR2 mutations in the genesis of a juvenile haemochromatosis phenotype, its applicability to haemochromatosis is still not commonly admitted. Criticisms are essentially focused on the very limited number of cases that have been reported to date and, taking into account this limitation, on a phenotypic variability that encompasses juvenile and adult haemochromatosis. $^{25}$ The nature of each of the mutations considered and the subsequent HFE/HAMP combination of heterozygous mutations would explain one aspect of this phenotypical heterogeneity. This possibility makes particular sense when considering the G71D HAMP mutation and, on the other hand, the H63D and S65C mutations which are deemed to be risk factors rather than causative mutations in HFE-related haemochromatosis. In addition, one can consider that, as reported for the main HFE causative genotype ( $\mathrm{C} 282 \mathrm{Y}$ homozygous), and probably to differing degrees for all forms of haemochromatosis, the HFE/HAMP digenic mode of inheritance is influenced by environmental factors and modifier genes. Right now, however, nobody can contest that novel cases would help to define and classify the HFE/HAMP digenic mode of inheritance in the haemochromatosis group. Further advances will surely accrue from better comprehension of the roles of HFE in iron metabolism - first confined to a repressive effect on the transferrin-transferrin receptor iron uptake pathway, then focused on a sensory function in the duodenal crypts, ${ }^{130}$ and now clearly opened to regulatory mechanisms in the hepatocytes and macrophages. ${ }^{49,82-85,131}$

\section{Conclusion}

We should keep in mind that the vast majority of haemochromatosis patients are homozygous for the ancestral HFE C282Y mutation, and that the combination of transferrin saturation measurement and genotyping of this predominant mutation has improved our ability to diagnose the disease and prevent morbid complications. We have recently shown that HFE C282Y mutation testing has modified the epidemiology of haemochromatosis, with the sex ratio reduced to close to 1.0 and a weaker clinical expression than observed previously. ${ }^{132}$ However, we should also be aware that the C282Y homozygous genotype is not fully penetrant and that its expression depends on the complex interplay of genetic and nongenetic factors. Several investigations are focusing on discovery of the genetic factors that enable us to identify more precisely those $\mathrm{C} 282 \mathrm{Y}$ homozygous patients at increased risk of developing clinical features.

In non-C282Y homozygous patients, we now know that a haemochromatosis phenotype can be associated either with another HFE mutation, especially H63D and S65C if they are inherited in-trans with $\mathrm{C} 282 \mathrm{Y}$, or with mutations in the genes that encode HAMP, HJV, TFR2 or ferroportin. The standard biochemical marker for all types of haemochromatosis is transferrin saturation, with the exception of the ferroportin disease for which a high-serum ferritin concentration can contrast with normal or slightly increased transferrin saturation. The expected transmission pattern (autosomal recessive or autosomal dominant), the course of the disease (juvenile, young adult or adult onset), the observation of particular symptoms (hypogonadism or unexplained heart failure are indicative of a juvenile haemochromatosis syndrome), and the predominant localization of hepatic iron (hepatocytes, Kupffer cells or both) can help in the decision to perform second-line genetic testing (the first test should be for the HFE C282Y and H63D mutation). ${ }^{133}$ However, as the HJV G320V and SLC40A1 V162del are the only common mutations of the non-HFE types of haemochromatosis, a general mutation strategy is required and the use of rapid, accurate and cheap scanning methods such as D-HPLC is highly recommended. $38,58,134$

Whether or not the general population should be screened for haemochromatosis is a source of continuing debate. ${ }^{135}$ However, there is no doubt that, once a diagnosis of haemochromatosis has been established in a proband, screening of family members, namely cascade screening, is efficient and cost-effective. This cascade screening should be based on both biochemical testing and genetic testing, if one or more pathogenic mutations have been identified. ${ }^{136}$

In the last few years, genetic, in vitro and animal model studies have shown that HAMP plays a central role in iron homeostasis. Therapeutic spin-offs can be expected from growing understanding of the roles of HAMP and identification of the factors that help to modulate its hepatic expression.

\section{Acknowledgements}

This work was supported by The Programme Hospitalier de Recherche Clinique 'Mise en place d'un diagnostic exhaustif des surcharges en fer primaires'. The Conseil Scientifique de I'Etablissement Français du Sang (projects 2003.19 et 2002.36).

\section{References}

1 Von Recklinghausen FD: Uber Hamochromatose. Berl Klin Wochenschr 1889; 26: 925.

2 Trousseau A: Glycosurie, diabète sucré. Clin Méd l'Hôtel Dieu de Paris 1865 ; 2 : 663-698.

3 Sheldon JH: Haemochromatosis. London, UK: Oxford University Press, 1935.

4 Simon M, Alexandre JL, Fauchet R, Genetet B, Bourel M: The genetics of hemochomatosis. Progr Med Genet 1980; 4: 135-168.

5 Saddi R, Feingold J: Idiopathic haemochromatosis: an autosomal recessive disease. Clin Genet 1974; 5: 234-241.

6 Simon M, Bourel M, Fauchet R, Genetet B: Association of HLAA3 and HLA-B14 antigens with idiopathic haemochromatosis. Gut 1976; 17: 332-334. 
7 Simon M, Le Mignon L, Fauchet R et al: A study of 609 HLA haplotypes marking for the hemochromatosis gene: (1) mapping of the gene near the HLA-A locus and characters required to define a heterozygous population and (2) hypothesis concerning the underlying cause of hemochromatosis-HLA association. Am J Hum Genet 1987; 41: 89-105.

8 Feder JN, Gnirke A, Thomas W et al: A novel MHC class I-like gene is mutated in patients with hereditary haemochromatosis. Nat Genet 1996; 13: 399-408.

9 Zhou XY, Tomatsu S, Fleming RE et al: HFE gene knockout produces mouse model of hereditary hemochromatosis. Proc Natl Acad Sci USA 1998; 95: 2492-2497.

10 Jazwinska EC, Pyper WR, Burt MJ et al: Haplotype analysis in Australian hemochromatosis patients: evidence for a predominant ancestral haplotype exclusively associated with hemochromatosis. Am J Hum Genet 1995; 56: 428-433.

11 Hanson EH, Imperatore G, Burke W: HFE gene and hereditary hemochromatosis: a HuGE review. Human Genome Epidemiology. Am J Epidemiol 2001; 154: 193-206.

12 Levy JE, Montross LK, Cohen DE, Fleming MD, Andrews NC: The C282Y mutation causing hereditary hemochromatosis does not produce a null allele. Blood 1999; 94: 9-11.

13 Dupradeau F, Altenberg-Greulich B, Warin R, Fuentes V, Monti J, Rochette J: A 3-dimensional model building by homology of the HFE protein: molecular consequences and application to antibody development. Biochim Biophys Acta 2000; 1481: 213-221.

14 Camaschella C, Roetto A, Cali A et al: The gene TFR2 is mutated in a new type of haemochromatosis mapping to 7q22. Nat Genet 2000; 25: 14-15.

15 Njajou OT, Vaessen N, Joosse M et al: A mutation in SLC11A3 is associated with autosomal dominant hemochromatosis. Nat Genet 2001; 28: 213-214.

16 Roetto A, Papanikolaou G, Politou M et al: Mutant antimicrobial peptide hepcidin is associated with severe juvenile hemochromatosis. Nat Genet 2003; 33: 21-22.

17 Papanikolaou G, Samuels ME, Ludwig EH et al: Mutations in HFE2 cause iron overload in chromosome 1q-linked juvenile hemochromatosis. Nat Genet 2004; 36: 77-82.

18 Jacolot S, Le Gac G, Scotet V, Quere I, Mura C, Ferec C: HAMP as a modifier gene that increases the phenotypic expression of the HFE pC282Y homozygous genotype. Blood 2004; 103: $2835-2840$.

19 Merryweather-Clarke AT, Cadet E, Bomford A et al: Digenic inheritance of mutations in HAMP and HFE results in different types of haemochromatosis. Hum Mol Genet 2003; 12: 2241-2247.

20 Adams P, Brissot P, Powell LW: EASL International Consensus Conference on haemochromatosis. J Hepatol 2000; 33: 485-504.

21 Camaschella C, Roetto A, De Gobbi M: Juvenile hemochromatosis. Semin Hematol 2002; 39: 242-248.

22 De Gobbi M, Roetto A, Piperno A et al: Natural history of juvenile haemochromatosis. Br J Haematol 2002; 117: 973-979.

23 Le Gac G, Mons F, Jacolot S, Scotet V, Ferec C, Frebourg T: Early onset hereditary hemochromatosis resulting from a novel TFR2 gene nonsense mutation (R105X) in two siblings of north French descent. Br J Haematol 2004; 125: 674-678.

24 Pietrangelo A: The ferroportin disease. Blood Cells Mol Dis 2004; 32: $131-138$

25 Roetto A, Camaschella C: New insights into iron homeostasis through the study of non-HFE hereditary haemochromatosis. Best Pract Res Clin Haematol 2005; 18: 235-250.

26 Cazzola M: Genetic disorders of iron overload and the novel 'ferroportin disease'. Haematologica 2003; 88: 721-724.

27 Merryweather-Clarke AT, Pointon JJ, Jouanolle AM, Rochette J, Robson KJ: Geography of HFE C282Y and H63D mutations. Genet Test 2000; 4: 183-198.

28 Burke W, Imperatore G, McDonnell SM, Baron RC, Khoury MJ: Contribution of different HFE genotypes to iron overload disease: a pooled analysis. Genet Med 2000; 2: 271-277.

29 Moirand R, Jouanolle AM, Brissot P, Le Gall JY, David V, Deugnier Y: Phenotypic expression of HFE mutations: a French study of 1110 unrelated iron-overloaded patients and relatives. Gastroenterology 1999; 116: 372-377.

30 Lucotte G: Frequency analysis and allele map in favor of the celtic origin of the C282Y mutation of hemochromatosis. Blood Cells Mol Dis 2001; 27: 549-556.

31 Ryan E, O'keane C, Crowe J: Hemochromatosis in Ireland and HFE. Blood Cells Mol Dis 1998; 24: 428-432.

32 Jackson HA, Carter K, Darke C et al: HFE mutations, iron deficiency and overload in 10,500 blood donors. Br J Haematol 2001; 114: 474-484.

33 Distante S, Robson KJ, Graham-Campbell J, Arnaiz-Villena A, Brissot P, Worwood M: The origin and spread of the HFE-C282Y haemochromatosis mutation. Hum Genet 2004; 115: 269-279.

34 Rochette J, Pointon JJ, Fisher CA et al: Multicentric origin of hemochromatosis gene (HFE) mutations. Am J Hum Genet 1999; 64: $1056-1062$.

35 Waalen J, Nordestgaard BG, Beutler E: The penetrance of hereditary hemochromatosis. Best Pract Res Clin Haematol 2005; 18: 203-220.

36 Datz C, Haas T, Rinner H, Sandhofer F, Patsch W, Paulweber B: Heterozygosity for the C282Y mutation in the hemochromatosis gene is associated with increased serum iron, transferrin saturation, and hemoglobin in young women: a protective role against iron deficiency? Clin Chem 1998; 44: 2429-2432.

37 Moalem S, Weinberg ED, Percy ME: Hemochromatosis and the enigma of misplaced iron: implications for infectious disease and survival. Biometals 2004; 17: 135-139.

38 Le Gac G, Mura C, Ferec C: Complete scanning of the hereditary hemochromatosis gene (HFE) by use of denaturing HPLC. Clin Chem 2001; 47: 1633-1640.

39 Camaschella C, Roetto A, De Gobbi M: Genetic haemochromatosis: genes and mutations associated with iron loading. Best Pract Res Clin Haematol 2002; 15: 261-276.

40 Mura C, Raguenes O, Ferec C: HFE mutations analysis in 711 hemochromatosis probands: evidence for S65C implication in mild form of hemochromatosis. Blood 1999; 93: 2502-2505

41 Holmstrom P, Marmur J, Eggertsen G, Gafvels M, Stal P: Mild iron overload in patients carrying the HFE S65C gene mutation: a retrospective study in patients with suspected iron overload and healthy controls. Gut 2002; 51: 723-730.

42 Wallace DF, Walker AP, Pietrangelo A et al: Frequency of the S65C mutation of HFE and iron overload in 309 subjects heterozygous for C282Y. J Hepatol 2002; 36: 474-479.

43 Asberg A, Thorstensen K, Hveem K, Bjerve KS: Hereditary hemochromatosis: the clinical significance of the S65C mutation. Genet Test 2002; 6: 59-62.

44 Trombini P, Mauri V, Salvioni A, Corengia C, Arosio C, Piperno A: S65c frequency in Italian patients with hemochromatosis, porphyria cutanea tarda and chronic viral hepatitis with iron overload. Haematologica 2001; 86: 316-317.

45 Piperno A, Arosio C, Fossati L et al: Two novel nonsense mutations of HFE gene in five unrelated Italian patients with hemochromatosis. Gastroenterology 2000; 119: 441-445.

46 Rosmorduc O, Poupon R, Nion I et al: Differential HFE allele expression in hemochromatosis heterozygotes. Gastroenterology 2000; 119: $1075-1086$.

47 Le Gac G, Dupradeau FY, Mura C et al: Phenotypic expression of the $\mathrm{C} 282 \mathrm{Y} / \mathrm{Q} 283 \mathrm{P}$ compound heterozygosity in HFE and molecular modeling of the Q283P mutation effect. Blood Cells Mol Dis 2003; 30: 231-237.

48 Ka C, Le Gac G, Dupradeau F-Y, Rochette J, Ferec C: The Q283P amino acid change in HFE leads to structural and functional consequences similar to those described for the mutated $282 \mathrm{Y}$ HFE protein. Hum Genet 2005, (in press)

49 Drakesmith H, Sweetland E, Schimanski L et al: The hemochromatosis protein HFE inhibits iron export from macrophages. Proc Natl Acad Sci USA 2002; 99: 15602-15607.

50 Finch SC, Finch CA: Idiopathic hemochromatosis an iron storage disease: A. Iron metabolism in hemochromatosis. Medecine 1955; 34: 381-430. 
51 Dadone MM, Kushner JP, Edwards CQ, Bishop DT, Skolnick MH: Hereditary hemochromatosis. Analysis of laboratory expression of the disease by genotype in 18 pedigrees. Am J Clin Pathol 1982; 78: 196-207.

52 Edwards CQ, Griffen LM, Goldgar D, Drummond C, Skolnick MH, Kushner JP: Prevalence of hemochromatosis among 11,065 presumably healthy blood donors. $N$ Engl J Med 1988; 318: $1355-1362$.

53 Wiggers P, Dalhoj J, Kiaer $\mathrm{H}$ et al: Screening for haemochromatosis: prevalence among Danish blood donors. J Intern Med 1991; 230: $265-270$.

54 Asberg A, Hveem K, Thorstensen $\mathrm{K}$ et al: Screening for hemochromatosis: high prevalence and low morbidity in an unselected population of 65,238 persons. Scand J Gastroenterol 2001; 36: 1108-1115.

55 Adams PC, Reboussin DM, Barton JC et al: Hemochromatosis and iron-overload screening in a racially diverse population. $N$ Engl J Med 2005; 352: 1769-1778.

56 Bomford A: Genetics of haemochromatosis. Lancet 2002; 360: $1673-1681$

57 Beutler E: The HFE Cys282Tyr mutation as a necessary but not sufficient cause of clinical hereditary hemochromatosis. Blood 2003; 101: 3347-3350.

58 Worwood M: Inherited iron loading: genetic testing in diagnosis and management. Blood Rev 2005; 19: 69-88.

59 Scotet V, Merour MC, Mercier AY et al: Hereditary hemochromatosis: effect of excessive alcohol consumption on disease expression in patients homozygous for the C282Y mutation. Am J Epidemiol 2003; 158: 129-134.

60 Fletcher LM, Bridle KR, Crawford DH: Effect of alcohol on iron storage diseases of the liver. Best Pract Res Clin Gastroenterol 2003; 17: $663-677$.

61 Levy JE, Montross LK, Andrews NC: Genes that modify the hemochromatosis phenotype in mice. J Clin Invest 2000; 105: $1209-1216$

62 Nicolas G, Andrews NC, Kahn A, Vaulont S: Hepcidin, a candidate modifier of the hemochromatosis phenotype in mice. Blood 2004; 103: 2841-2843.

63 Bensaid M, Fruchon S, Mazeres C, Bahram S, Roth MP, Coppin H: Multigenic control of hepatic iron loading in a murine model of hemochromatosis. Gastroenterology 2004; 126: $1400-1408$.

64 Le Gac G, Scotet V, Ka C et al: The recently identified type $2 \mathrm{~A}$ juvenile haemochromatosis gene (HJV), a second candidate modifier of the C282Y homozygous phenotype. Hum Mol Genet 2004; 13: 1913-1918.

65 Livesey KJ, Wimhurst VL, Carter K et al: The 16189 variant of mitochondrial DNA occurs more frequently in C282Y homozygotes with haemochromatosis than those without iron loading. J Med Genet 2004; 41: 6-10.

66 Roetto A, Totaro A, Cazzola M et al: Juvenile hemochromatosis locus maps to chromosome 1q. Am J Hum Genet 1999; 64: $1388-1393$.

67 Lanzara C, Roetto A, Daraio F et al: Spectrum of hemojuvelin gene mutations in 1q-linked juvenile hemochromatosis. Blood 2004; 103: 4317-4321.

68 Lee PL, Beutler E, Rao SV, Barton JC: Genetic abnormalities and juvenile hemochromatosis: mutations of the HJV gene encoding hemojuvelin. Blood 2004; 103: 4669-4671.

69 Gehrke SG, Pietrangelo A, Kascak M et al: HJV gene mutations in European patients with juvenile hemochromatosis. Clin Genet 2005; 67: 425-428.

70 Huang FW, Rubio-Aliaga I, Kushner JP, Andrews NC, Fleming MD: Identification of a novel mutation (C321X) in HJV. Blood 2004; 104: 2176-2177.

71 Wallace DF, Dixon JL, Ramm GA, Anderson GJ, Powell LW, Subramaniam N: Hemojuvelin (HJV)-associated hemochromatosis: analysis of HJV and HFE mutations and iron overload in three families. Haematologica 2005; 90: 254-255.
72 Janosi A, Andrikovics H, Vas K et al: Homozygosity for a novel nonsense mutation (G66X) of the HJV gene causes severe juvenile hemochromatosis with fatal cardiomyopathy. Blood 2005; 105: 432.

73 Majore S, Binni F, Pennese A, De Santis A, Crisi A, Grammatico P: HAMP gene mutation c.208T $>C$ (p.C70R) identified in an Italian patient with severe hereditary hemochromatosis. Hum Mutat 2004; 23: 400.

74 Roetto A, Daraio F, Porporato P et al: Screening hepcidin for mutations in juvenile hemochromatosis: identification of a new mutation (C70R). Blood 2004; 103: 2407-2409.

75 Delatycki MB, Allen KJ, Gow P et al: A homozygous HAMP mutation in a multiply consanguineous family with pseudodominant juvenile hemochromatosis. Clin Genet 2004; 65: $378-383$.

76 Matthes T, Aguilar-Martinez P, Pizzi-Bosman L et al: Severe hemochromatosis in a Portuguese family associated with a new mutation in the 5'-UTR of the HAMP gene. Blood 2004; 104: $2181-2183$.

77 Krause A, Neitz S, Magert HJ et al: LEAP-1, a novel highly disulfide-bonded human peptide, exhibits antimicrobial activity. FEBS Lett 2000; 480: 147-150.

78 Park $\mathrm{CH}$, Valore EV, Waring AJ, Ganz T: Hepcidin, a urinary antimicrobial peptide synthesized in the liver. J Biol Chem 2001; 276: 7806-7810.

79 Pigeon C, Ilyin G, Courselaud B et al: A new mouse liver-specific gene, encoding a protein homologous to human antimicrobial peptide hepcidin, is overexpressed during iron overload. J Biol Chem 2001; 276: 7811-7819.

80 Nicolas G, Bennoun M, Devaux I et al: Lack of hepcidin gene expression and severe tissue iron overload in upstream stimulatory factor 2 (USF2) knockout mice. Proc Natl Acad Sci USA 2001; 98: 8780-8785.

81 Nicolas G, Bennoun M, Porteu A et al: Severe iron deficiency anemia in transgenic mice expressing liver hepcidin. Proc Natl Acad Sci USA 2002; 99: 4596-4601.

82 Ganz T: Hepcidin - a regulator of intestinal iron absorption and iron recycling by macrophages. Best Pract Res Clin Haematol 2005; 18: 171-182.

83 Roy CN, Andrews NC: Anemia of inflammation: the hepcidin link. Curr Opin Hematol 2005; 12: 107-111.

84 Fleming RE, Bacon BR: Orchestration of iron homeostasis. N Engl $J$ Med 2005; 352: 1741-1744.

85 Leong WI, Lonnerdal B: Hepcidin, the recently identified peptide that appears to regulate iron absorption. J Nutr 2004; 134: $1-4$.

86 Nemeth E, Tuttle MS, Powelson J et al: Hepcidin regulates cellular iron efflux by binding to ferroportin and inducing its internalization. Science 2004; 306: 2090-2093.

87 Bridle KR, Frazer DM, Wilkins SJ et al: Disrupted hepcidin regulation in HFE-associated haemochromatosis and the liver as a regulator of body iron homoeostasis. Lancet 2003; 361: 669-673.

88 Ahmad KA, Ahmann JR, Migas MC et al: Decreased liver hepcidin expression in the Hfe knockout mouse. Blood Cells Mol Dis 2002; 29: 361-366.

89 Nemeth E, Roetto A, Garozzo G, Ganz T, Camaschella C: Hepcidin is decreased in TFR2 hemochromatosis. Blood 2005; 105: 1803-1806.

90 Kawabata H, Fleming RE, Gui D et al: Expression of hepcidin is down-regulated in TFR2 mutant mice manifesting a phenotype of hereditary hemochromatosis. Blood 2005; 105: 376-381.

91 Fleming RE, Ahmann JR, Migas MC et al: Targeted mutagenesis of the murine transferrin receptor- 2 gene produces hemochromatosis. Proc Natl Acad Sci USA 2002; 99: 10653-10658.

92 Hattori A, Wakusawa S, Hayashi H et al: AVAQ 594-597 deletion of the TFR2 gene in a Japanese family with hemochromatosis. Hepatol Res 2003; 26: 154-156.

93 Roetto A, Totaro A, Piperno A et al: New mutations inactivating transferrin receptor 2 in hemochromatosis type 3. Blood 2001; 97: 2555-2560. 
94 Girelli D, Bozzini C, Roetto A et al: Clinical and pathologic findings in hemochromatosis type 3 due to a novel mutation in transferrin receptor 2 gene. Gastroenterology 2002; 122: $1295-1302$.

95 Mattman A, Huntsman D, Lockitch G et al: Transferrin receptor 2 (TFR2) and HFE mutational analysis in non-C282Y iron overload: identification of a novel TFR2 mutation. Blood 2002; 100: $1075-1077$.

96 Pietrangelo A, Caleffi A, Henrion J et al: Juvenile hemochromatosis associated with pathogenic mutations of adult hemochromatosis genes. Gastroenterology 2005; 128: 470-479.

97 Koyama C, Wakusawa S, Hayashi $\mathrm{H}$ et al: Two novel mutations, L490R and V561X, of the transferrin receptor 2 gene in Japanese patients with hemochromatosis. Haematologica 2005; 90: 302-307.

98 Kawabata H, Yang R, Hirama $\mathrm{T}$ et al: Molecular cloning of transferrin receptor 2. A new member of the transferrin receptorlike family. J Biol Chem 1999; 274: 20826-20832.

99 Fleming RE, Migas MC, Holden CC et al: Transferrin receptor 2: continued expression in mouse liver in the face of iron overload and in hereditary hemochromatosis. Proc Natl Acad Sci USA 2000; 97: 2214-2219.

100 Zhang AS, Xiong S, Tsukamoto H, Enns CA: Localization of iron metabolism-related mRNAs in rat liver indicate that HFE is expressed predominantly in hepatocytes. Blood 2004; 103: $1509-1514$.

101 Kawabata H, Germain RS, Vuong PT, Nakamaki T, Said JW, Koeffler HP: Transferrin receptor 2-alpha supports cell growth both in iron-chelated cultured cells and in vivo. J Biol Chem 2000; 275: $16618-16625$.

102 Johnson MB, Enns CA: Diferric transferrin regulates transferrin receptor 2 protein stability. Blood 2004; 104: 4287-4293.

103 Robb A, Wessling-Resnick M: Regulation of transferrin receptor 2 protein levels by transferrin. Blood 2004; 104: 4294-4299.

104 Eason RJ, Adams PC, Aston CE, Searle J: Familial iron overload with possible autosomal dominant inheritance. Aust NZ J Med 1990; 20: 226-230.

105 Pietrangelo A, Montosi G, Totaro A et al: Hereditary hemochromatosis in adults without pathogenic mutations in the hemochromatosis gene. N Engl J Med 1999; 341: 725-732.

106 Montosi G, Donovan A, Totaro A et al: Autosomal-dominant hemochromatosis is associated with a mutation in the ferroportin (SLC11A3) gene. J Clin Invest 2001; 108: 619-623.

107 Arden KE, Wallace DF, Dixon JL et al: A novel mutation in ferroportin1 is associated with haemochromatosis in a Solomon Islands patient. Gut 2003; 52: 1215-1217.

108 Cazzola M, Cremonesi L, Papaioannou M et al: Genetic hyperferritinaemia and reticuloendothelial iron overload associated with a three base pair deletion in the coding region of the ferroportin gene (SLC11A3). Br J Haematol 2002; 119: 539-546.

109 Devalia V, Carter K, Walker AP et al: Autosomal dominant reticuloendothelial iron overload associated with a 3-base pair deletion in the ferroportin 1 gene (SLC11A3). Blood 2002; 100: 695-697.

110 Wallace DF, Pedersen P, Dixon JL et al: Novel mutation in ferroportin1 is associated with autosomal dominant hemochromatosis. Blood 2002; 100: 692-694.

111 Roetto A, Merryweather-Clarke AT, Daraio F et al: A valine deletion of ferroportin 1: a common mutation in hemochromastosis type 4. Blood 2002; 100: 733-734.

112 Barton JC, Acton RT, Rivers CA et al: Genotypic and phenotypic heterogeneity of African Americans with primary iron overload. Blood Cells Mol Dis 2003; 31: 310-319.

113 Gordeuk VR, Caleffi A, Corradini E et al: Iron overload in Africans and African-Americans and a common mutation in the SCL40A1 (ferroportin 1) gene. Blood Cells Mol Dis 2003; 31: 299-304.

114 Beutler E, Barton JC, Felitti VJ et al: Ferroportin 1 (SCL40A1) variant associated with iron overload in African-Americans. Blood Cells Mol Dis 2003; 31: 305-309.
115 Schimanski LM, Drakesmith H, Merryweather-Clarke AT et al: In vitro functional analysis of human ferroportin (FPN) and hemochromatosis-associated FPN mutations. Blood 2005; 105: 4096-4102.

116 Robson KJ, Merryweather-Clarke AT, Cadet E et al: Recent advances in understanding haemochromatosis: a transition state. J Med Genet 2004; 41: 721-730.

117 Donovan A, Brownlie A, Zhou Y et al: Positional cloning of zebrafish ferroportin1 identifies a conserved vertebrate iron exporter. Nature 2000; 403: 776-781.

118 McKie AT, Marciani P, Rolfs A et al: A novel duodenal ironregulated transporter, IREG1, implicated in the basolateral transfer of iron to the circulation. Mol Cell 2000; 5: 299-309.

119 Abboud S, Haile DJ: A novel mammalian iron-regulated protein involved in intracellular iron metabolism. J Biol Chem 2000; 275: 19906-19912.

120 Fleming RE, Sly WS: Ferroportin mutation in autosomal dominant hemochromatosis: loss of function, gain in understanding. J Clin Invest 2001; 108: 521-522.

121 Drakesmith H, Schimanski LM, Ormerod E et al: Resistance to hepcidin is conferred by hemochromatosis-associated mutations of ferroportin. Blood 2005; 106: 1092-1097.

122 Knutson M, Wessling-Resnick M: Iron metabolism in the reticuloendothelial system. Crit Rev Biochem Mol Biol 2003; 38: 61-88.

123 Papanikolaou G, Tzilianos M, Christakis JI et al: Hepcidin in iron overload disorders. Blood 2005; 105: 4103-4105.

124 Rivard SR, Lanzara C, Grimard D et al: Autosomal dominant reticuloendothelial iron overload (HFE type 4) due to a new missense mutation in the FERROPORTIN 1 gene (SLC11A3) in a large French-Canadian family. Haematologica 2003; 88: $824-826$.

125 Sham RL, Phatak PD, West C, Lee P, Andrews C, Beutler E: Autosomal dominant hereditary hemochromatosis associated with a novel ferroportin mutation and unique clinical features. Blood Cells Mol Dis 2005; 34: 157-161.

126 Wallace DF, Clark RM, Harley HA, Subramaniam VN: Autosomal dominant iron overload due to a novel mutation of ferroportin1 associated with parenchymal iron loading and cirrhosis. J Hepatol 2004; 40: 710-713.

127 Njajou OT, de Jong G, Berghuis B et al: Dominant hemochromatosis due to $\mathrm{N} 144 \mathrm{H}$ mutation of SLC11A3: clinical and biological characteristics. Blood Cells Mol Dis 2002; 29: 439-443.

128 Njajou OT, Vaessen N, Oostra B, Heutink P, van Duijn CM: The hemochromatosis $\mathrm{N} 144 \mathrm{H}$ mutation of SLC11A3 gene in patients with type 2 diabetes. Mol Genet Metab 2002; 75: 290-291.

129 Ming JE, Muenke M: Multiple hits during early embryonic development: digenic diseases and holoprosencephaly. Am J Hum Genet 2002; 71: 1017-1032.

130 Townsend A, Drakesmith H: Role of HFE in iron metabolism, hereditary haemochromatosis, anaemia of chronic disease, and secondary iron overload. Lancet 2002; 359: 786-790.

131 Mura C, Le Gac G, Jacolot S, Ferec C: Transcriptional regulation of the human HFE gene indicates high liver expression and erythropoiesis coregulation. FASEB J 2004; 18: 1922-1924.

132 Scotet V, Le Gac G, Merour MC et al: Impact of HFE testing on clinical presentation of hereditary hemochromatosis: new epidemiological data. BMC Med Genet 2005; 6: 24 .

133 Pietrangelo A: Hereditary hemochromatosis - a new look at an old disease. N Engl J Med 2004; 350: 2383-2397.

134 Biasiotto G, Belloli S, Ruggeri G et al: Identification of new mutations of the HFE, hepcidin, and transferrin receptor 2 genes by denaturing HPLC analysis of individuals with biochemical indications of iron overload. Clin Chem 2003; 49: 1981-1988.

135 McCullen MA, Crawford DH, Hickman PE: Screening for hemochromatosis. Clin Chim Acta 2002; 315: 169-186.

136 Krawczak M, Cooper DN, Schmidtke J: Estimating the efficacy and efficiency of cascade genetic screening. Am J Hum Genet 2001; 69: 361-370. 